\title{
The Informational Role of Spot Prices and Inventories
}

\author{
by \\ James L. Smith, Rex Thompson, and Thomas K. Lee*
}

March 31, 2012

Revised: February 1, 2013

\begin{abstract}
We examine the role that spot markets and physical inventories play in revealing the expectations of informed traders to uninformed traders. Using a rational expectations approach, we show that equilibrium differences in beliefs are determined by characteristics of the underlying commodity, including storage costs, the amplitude of demand and supply shocks, the accuracy of information available to informed investors, the numbers of informed and uninformed traders, and the elasticity of demand and supply. We also show that passive investors impede the revelation of information in the spot market, which magnifies the equilibrium difference in beliefs. Because the incentive for speculative trading in futures contracts stems directly from the failure of spot markets to eliminate differences in beliefs, our results provide insight into why and how the amount of speculative futures trading varies across commodities, as well as through time.
\end{abstract}

Key Words: futures trading, speculation, inventories, private information

JEL Classification Numbers: D82, D84, G13, G14

*Smith and Thompson are with the Department of Finance, Southern Methodist University, Dallas, Texas. Lee is with the U.S. Energy Information Administration, Washington, DC. The authors thank Ron Alquist, Christiane Baumeister, Lutz Kilian, John Parsons, and Ine Van Robays for comments on an earlier draft, and also thank Huilin Ni for providing research assistance. The authors gratefully acknowledge financial support received from the U.S. Energy Information Administration. In addition, Smith's participation in this research was supported by Resources for the Future (Washington DC) and the King Abdullah Petroleum Studies and Research Center (Riyadh, Saudi Arabia). None of these organizations are responsible for the contents of the present paper, nor should they be assumed to endorse the findings and conclusions reported herein. 


\section{The Informational Role of Spot Prices and Inventories}

\section{Overview}

We explore the role that spot markets and physical inventories play in revealing to uninformed traders the expectations of informed traders. We show how the dissemination of information is determined by specific characteristics of the commodity in question, including storage costs, the amplitude of unexpected demand and supply shocks, the accuracy of information acquired by informed investors, the numbers of informed and uninformed investors, and the elasticity of demand and supply for the commodity in question. We also show that the presence of passive investors (i.e., those taking positions without a view of future price movements) impedes the revelation of private information. Depending on all these factors, the resulting equilibrium difference in beliefs between informed and uninformed investors may be large or small.

Our analysis bears directly on the question of whether the degree of financial speculation in the futures markets has become excessive, as certain parties allege. As Grossman (1977) argues, the volume of futures trading is determined by two factors: differences in beliefs and hedging. In markets where spot trading completely reveals the information held by informed traders, all differences in beliefs are eliminated and speculative futures trading could not occur. If revelation is incomplete, however, differences in beliefs will exist and lead to speculative trading among differently informed investors. Thus, to the extent that the revelation of private information is incomplete, but varies across commodities, or across time for a given commodity, the scope for financial speculation in the respective futures markets also must vary. ${ }^{1}$ Thus, our results show how the scope of financial speculation depends on fundamental characteristics of the commodities and markets in question.

\footnotetext{
${ }^{1}$ As Grossman (1977) pointed out, the size of speculative futures trading relates to the difference in profits between informed and uninformed firms, which is proportional (in our model as in Grossman) to the size of the difference in beliefs.
} 
Variation in the degree of speculation in futures markets is substantial, both across commodities and across time, as shown in Figure 1 (next page). ${ }^{2}$ Thus, an inquiry into the structural causes of this variation is hardly an idle pursuit. Although systematic empirical tests of our model are beyond the scope of the present paper, one immediate conclusion from Figure 1 is that futures contracts on feeder cattle and natural gas are prone to an exceptionally high degree of speculative trading. Since high storage costs are one factor which, according to our analysis, impairs the revelation of private information and therefore generates large differences in beliefs, it may not be coincidental that these two commodities are also recognized as having relatively high storage costs. ${ }^{3}$ A much more refined empirical analysis is required to prove the point, but to the extent that speculative futures trading in any commodity is judged by regulatory authorities to be excessive, the cure for the problem (or at least its cause) may relate to fundamental characteristics of the commodity itself, rather than the motives or characteristics of the traders who participate in the market.

Our research objective consists of two parts: (a) to set forth a rational theory of spot market prices that illuminates the factors pertinent to the revelation of information, and (b) to develop testable implications regarding the resulting scope for speculation in the futures market. After a brief review of related literature in Section 2, we characterize the rational expectations equilibrium in the spot market, including the equilibrium difference in beliefs between informed and uninformed traders, in Section 3. The comparative static properties of this model are developed in Section 4, where the number and types of traders is taken as fixed. Passive investors are introduced in Section 5, and the implications of endogenous entry and exit of

\footnotetext{
${ }^{2}$ The figure shows Working's T statistic (the speculative index) for seventeen commodities traded on the Nymex market. Each index is computed as a rolling five-week average from data contained in the weekly Disaggregated Commitment of Traders report released by the U.S. Commodity Futures Trading Commission.

${ }^{3}$ Storage of natural gas is expensive due to the low energy intensity of the fuel. The cost of "storing" feeder cattle, which are by definition young animals, is high (even relative to other livestock) because the cattle are transformed into older animals during "storage."
} 
traders are explored in Section 6. In the concluding Section 7 we summarize the main conclusions.

Figure 1: Workings' Speculative Index for Futures Contracts on the NYMEX Exchange

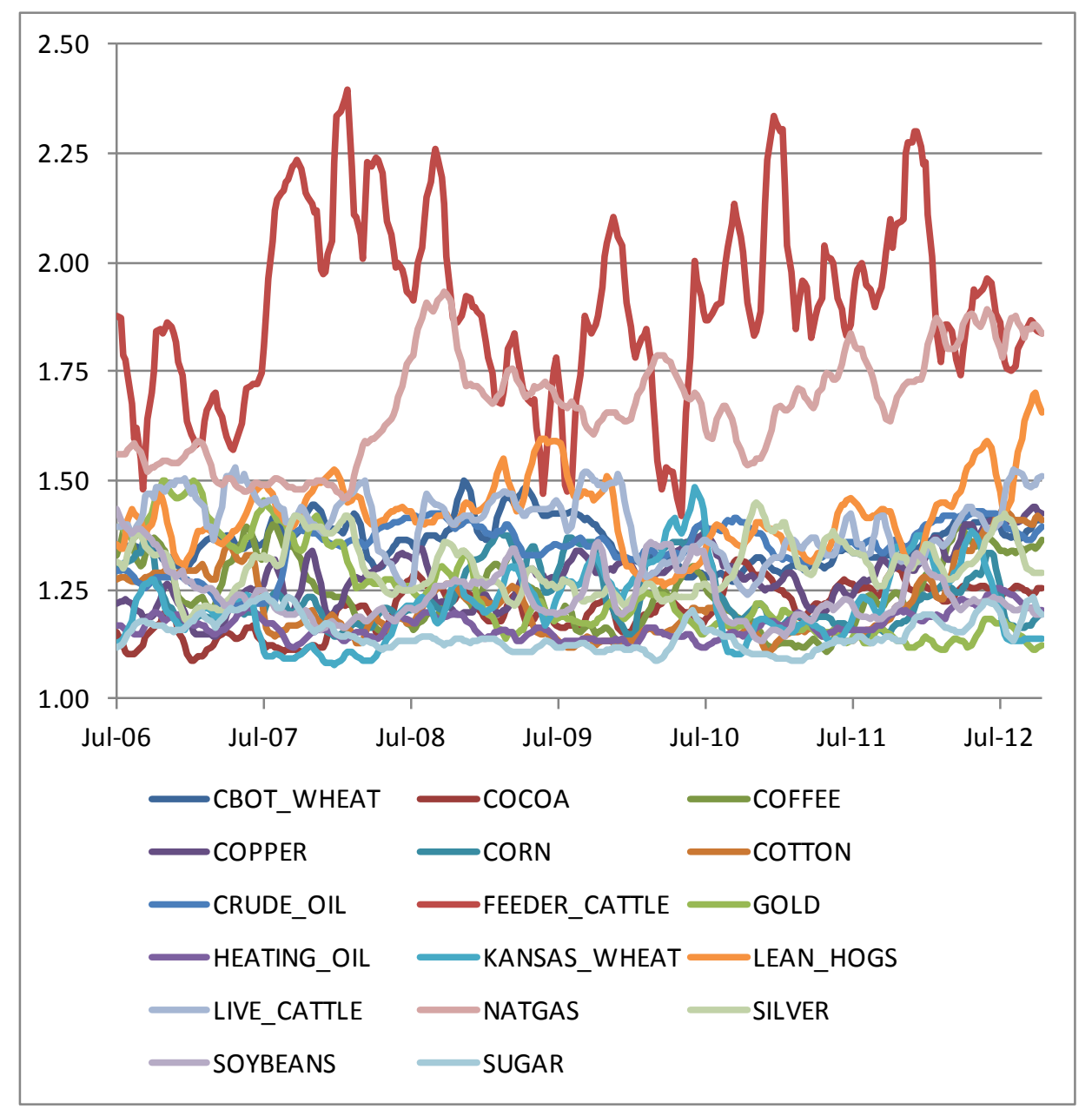

\section{Related Literature}

It is well known that spot prices of storable commodities reveal information about the future expectations of traders. For example, the standard Hotelling (1931) theory of intertemporal equilibrium for an exhaustible resource (like oil) determines the current price of a commodity as a function of expectations regarding future supply and demand for that commodity. As public expectations regarding future supply and demand change, then so too must the current price. Alquist and Kilian (2010) develop a highly stylized general equilibrium model of the oil market that demonstrates how shifts in uncertainty surrounding future supply 
(as distinct from shifts in the expected level of future supply) may also affect the spot price of oil. The impact of expectations regarding future market conditions on spot prices is believed to work in practice as well as theory, as indicated by Feldstein's (2008) suggestion to bring down the spot price of crude oil by enhancing the investment climate for future exploration, and the sometimes dramatic impact on spot prices of periodic revisions to U.S. Department of Agriculture predictions of future crop harvest levels, as reported by Pleven and Moffett (2012).

Our interest lies in a different direction. No doubt spot prices reflect consensus expectations of future market conditions if such a consensus is known to exist. But suppose it does not. Suppose instead that certain investors invest to acquire information that provides more accurate predictions about future conditions, whereas others do not. Assuming all traders are rational, we ask whether informed traders' participation in the spot market will reveal their information to those who were previously uninformed. This is not an all-or-nothing proposition; we mean to explore the extent to which private information acquired by informed traders is revealed, and the factors on which this determination rests.

Although a large literature investigates the potential mechanisms by which futures markets may disseminate private information, the role of spot markets has not been examined in comparable detail. ${ }^{4}$ Stein's (1987) model is a notable exception. It focuses directly on the revelation of private information in spot and futures prices, and (like us) highlights the role played by inventories. Although Stein's two types of traders are assumed to hold different information, neither can be said to be better informed than the other; spot traders are assumed to hold better information regarding one type of shock whereas futures traders are assumed to hold better information regarding another type of shock. In such a model, an increase in the number of informed futures traders can actually muddle the information held by spot traders,

\footnotetext{
${ }^{4}$ This was recognized years ago by Working (1942, p. 50), who observed: “Anticipations of all manner of developments that are thought to be predictable play a part in determining the price of a future. The error of the common theory has lain merely in supposing that the prices of futures, or of some particular futures, tend to be more strongly influenced by these anticipations than are spot prices."
} 
which may have a destabilizing effect on prices. Our model also has two trader types, but differs in assuming that one type is unambiguously better informed than the other.

Previous researchers, including Milgrom and Stokey (1982) and Tirole (1982), have demonstrated that, in an economy with complete markets and rational expectations, and subject to various other restrictions, no difference in beliefs can persist in equilibrium. Any private information initially held by certain traders is disseminated to all through the price mechanism and becomes common knowledge. Such an economy might include not only a complete set of futures markets for each commodity, but a complete set of contingent claims contracts as well, but no speculative trading. Grossman (1977) and Grossman and Stiglitz (1980) demonstrate conditions under which futures markets and equilibrium futures prices effectively disseminate all private information to the market at large, but they also recognize that transaction costs and information costs place limits on the market mechanism that might lead to equilibrium differences in investors' beliefs.

Regarding the empirical literature, Kilian and Murphy (2012) estimate a structural vector autoregressive model in which inventories signal market expectations. Like us, they focus on modeling the price of oil in the spot market, where physical inventories play a key role in revealing information about the future. Unlike us, however, their model does not admit heterogeneity of beliefs and does not attempt to explain the volume of speculative trading in futures markets.

We demonstrate that even in the absence of futures markets (or any more complete market in contingent claims), rational expectations render spot markets effective at revealing some private information. The extent of revelation determines, in turn, the magnitude of resulting differences in beliefs, which may be large or small depending on characteristics of the commodity in question. The informational role of spot prices may, therefore, vary significantly across the set of traded commodities. We are not aware of any previous literature that has examined this aspect of spot markets, or that has considered how the informational role of spot 
prices varies across commodities as a predictor of the scope of speculative futures trading. And, by drawing on rational expectations, our analysis marks a departure from the growing literature on behavioral explanations of "differences in beliefs" that are created when certain traders fail to take into account all of the information that is available to them, as in Hong and Stein (2007).

\section{Rational Expectations Equilibrium in the Spot Market for a Storable Commodity}

To frame these questions in a familiar but rigorous context, we adapt and extend Grossman's (1977) analysis of rational expectations equilibrium for a storable commodity, like wheat. The commodity can be produced only during certain parts of the year, but people want to consume it throughout the year. Following Grossman, we assume that the year's harvest, $Q$, is fixed exogenously and that consumers' demand for wheat in each period depends only on that period's price, according to the function:

$$
D=D\left(P_{t}, w_{t}\right) \text { for } t=1,2
$$

where $P_{t}$ represents the period price of wheat and the $w_{t}$ represent stochastic demand shocks that are assumed to follow independent normal distributions with zero mean and standard deviation given by $\sigma$. We assume that $\partial D / \partial P<0$ and $\partial D / \partial w>0 .^{5}$

In addition to consumers, the market also contains firms that purchase and store wheat from one harvest to the next, which effects an inter-temporal allocation of the harvest. We will assume that some of these firms are "informed," meaning that at the opening of the period 1 spot market they observe $w_{1}$ directly and also acquire a signal, $\theta$, that is correlated with the future demand shock $w_{2}$. We assume that $\theta$ and $w_{2}$ are jointly normally distributed with correlation coefficient $\rho$. Obviously, the quality of informed firms' estimate of future demand

\footnotetext{
${ }^{5}$ The assumption that supply is fixed is for notational convenience and does not affect the results. Supply shocks can be incorporated explicitly, or (as we have done) simply subsumed in $w_{1}$. That is, suppose the harvest is given by $\mathrm{Q}+\varepsilon_{s}$, where $\varepsilon_{s}$ represents a supply shock, and let $\varepsilon_{d}$ represent the shock to demand. If we then define $w_{1}=\varepsilon_{d}-\varepsilon_{s}$ as the shock to the net demand curve, the model developed in the text follows directly.
} 
increases in $\rho$. The conditional density of $w_{2}$ given $\theta$ is also normal and is denoted $f\left(w_{2} \mid \theta\right)$, and informed firms use this distribution in addition to their knowledge of $w_{1}$ to make inferences about future demand and future price. Uninformed firms observe neither $w_{1}$ or $\theta$, but know the marginal density, $\mu(\theta)$, and observe the first period price; and are therefore assumed to make inferences about future demand and price using $P_{1}$ and $\int f\left(w_{2} \mid \theta\right) \mu(\theta) d \theta .^{6}$

Using all information at their disposal, each type of firm is assumed to purchase first period inventories to maximize expected profits. If $C(I)$ represents the cost of holding inventory level $I$, then each uninformed firm must solve: $\max _{I}: E\left[\pi^{a}\right]=\left(E\left[P_{2} \mid P_{1}\right]-P_{1}\right) I-C(I)$ to obtain an inventory supply function, $I^{a}=S^{a}\left(P_{1}\right)$ that satisfies the first-order condition:

$$
E\left[P_{2} \mid P_{1}\right]-P_{1}=M C\left(I^{a}\right),
$$

where $M C(\cdot)$ represents the firm's marginal cost of inventory. Likewise, each informed firm must solve: $\max _{I}: E\left[\pi^{b}\right]=\left(E\left[P_{2} \mid w_{1}, \theta\right]-P_{1}\right) I-C(I)$ to obtain an inventory supply function, $I^{b}=$ $S^{b}\left(w_{1}, \theta, P_{1}\right)$ that satisfies: ${ }^{7}$

$$
E\left[P_{2} \mid w_{1}, \theta\right]-P_{1}=M C\left(I^{b}\right)
$$

Whereas Grossman (1977) assumed only one firm of each type, we allow $m$ uninformed firms and $n$ informed firms. For the present, we will assume that $m$ and $n$ are determined exogenously. Therefore, total inventories carried over from first to second period are given by:

$$
\vartheta=m \times S^{a}\left(P_{1}\right)+n \times S^{b}\left(w_{1}, \theta, P_{1}\right) .
$$

\footnotetext{
${ }^{6}$ Our distinction between informed and uninformed investors is consistent with Baumeister and Kilian (2011), who demonstrate empirically that real-time data on oil market conditions enhance the accuracy of oil price forecasts.

${ }^{7}$ Although we assume that investors must purchase their holdings of the commodity, nothing changes if we assume the initial endowment $(\mathrm{Q})$ is owned by them, in which case they could be viewed as "producers" who may elect to either sell immediately or retain inventory for future sale. For example, in the case of an uninformed investor who is endowed with a portion $Q_{i}$ of the fixed supply, the profit function is given by: $\max _{I}: E\left[\pi^{a}\right]=$ $E P 2|P 1 I-C I+P 1 Q i-I=E P 2| P 1-P 1 I-C I+P 1 Q i$, which corresponds to the profit function given in the text except for the last term, which represents the value of the investor's initial endowment. Because the value of the endowment is independent of $I$, it does not alter the investor's behavior. The same is true of any informed investor who happens to own a portion of the initial endowment.
} 
For the given number of firms $(m, n)$, we now define a rational expectations equilibrium as a pair of mappings $\left(\tilde{P}_{1}, \tilde{P}_{2}\right)$ such that: ${ }^{8}$

$$
P_{1}(\cdot) \stackrel{\text { def }}{=} P_{1}^{e}\left(w_{1}, \theta\right), \quad P_{2}(\cdot) \stackrel{\text { def }}{=} P_{2}^{e}\left(w_{1}, w_{2}, \theta\right)
$$

and

$$
\begin{aligned}
& D\left[P_{1}^{e}\left(w_{1}, \theta\right)\right]=Q-\vartheta^{e}\left(w_{1}, \theta\right) \\
& D\left[P_{2}^{e}\left(w_{1}, w_{2}, \theta\right)\right]=\vartheta^{e}\left(w_{1}, \theta\right) \\
& \vartheta^{e}\left(w_{1}, \theta\right) \stackrel{\text { def }}{=} m \times S^{a}\left\{E\left[\tilde{P}_{2} \mid \tilde{P}_{1}=P_{1}^{e}\left(w_{1}, \theta\right)\right]-P_{1}^{e}\left(w_{1}, \theta\right)\right\}+n \times S^{b}\left\{E\left[\tilde{P}_{2} \mid w_{1}, \theta\right]-P_{1}^{e}\left(w_{1}, \theta\right)\right\}
\end{aligned}
$$

for all $w_{1}, w_{2}$, and $\theta$; and where:

$$
E\left[\tilde{P}_{2} \mid w_{1}, \theta\right] \stackrel{\text { def }}{=} \int_{-\infty}^{\infty} P_{2}^{e}\left(w_{1}, w_{2}, \theta\right) f\left(w_{2} \mid \theta\right) d w_{2}
$$

Assuming there to be only one trader of each type, Grossman (1977) demonstrated that $P_{1}^{e}$ fails to fully reveal the private information held by the informed investor, except in some degenerate cases. This remains true when multiple traders are involved, but as we show below, the extent to which private information is revealed varies with the relative numbers of informed and uninformed traders, and depends as well on fundamental characteristics of the commodity in question. The equilibrium difference in beliefs about $\widetilde{P}_{2}$, which is denoted $\Delta\left(w_{1}, \theta\right)$ is defined as:

$$
\Delta\left(w_{1}, \theta\right) \stackrel{\text { def }}{=} E\left[\tilde{P}_{2} \mid w_{1}, \theta\right]-E\left[\tilde{P}_{2} \mid \tilde{P}_{1}=P_{1}^{e}\left(w_{1}, \theta\right)\right]
$$

In particular, by examining the structure of $\Delta\left(w_{1}, \theta\right)$ we are able to discover the extent to which $P_{1}^{e}\left(w_{1}, \theta\right)$ reveals the quantity $E\left[\tilde{P}_{2} \mid w_{1}, \theta\right]$ to uninformed firms, and to identify the factors that produce more complete revelation.

\footnotetext{
${ }^{8}$ Grossman's (1977) proofs of the existence and uniqueness of equilibrium easily generalize to this case, which differs only in terms of the numbers of informed and uninformed firms.
} 
To proceed, we adopt the same linear demand functions that Grossman employed.

Thus, from this point we assume:

$$
D_{t}=k+\frac{1}{h} P_{t}+w_{t} \text { for } t=1,2
$$

Another significant departure from Grossman (1977) is that we assume that inventory costs depend on whether stocks are held separately by individual firms or pooled in a common storage facility. Grossman assumed separate holdings, with each firm's cost determined by the size of its own inventory according to $C(I)=c I^{2} / 2 .{ }^{9}$ If inventories are pooled, however, the aggregate (industry wide) cost would be given by $C(\vartheta)=c \vartheta^{2} / 2$, where $\vartheta=\sum_{j} I_{j}$ represents the combined inventory of all firms.

It seems reasonable to assume that a shared inventory facility would operate like a public utility subject to cost-of-service rate regulation, in which case each firm would be charged the same amount, $c \vartheta / 2$, per unit held in storage. ${ }^{10}$ Thus, an individual firm's storage cost can be represented as a function of its own inventory and the stock held by others:

$$
C(I \mid \vartheta)=\frac{c I^{2}}{2}+\iota \frac{c I(\vartheta-I)}{2}
$$

where $\iota$ is a variable that indicates whether inventories are shared $(\iota=1)$ or separate $(\iota=0){ }^{11}$ To the extent that investors enjoy a convenience yield from their holding of inventory, it is understood that (12a) represents the holding cost net of the convenience yield. The firm's marginal storage cost is accordingly:

$$
M C(I \mid \vartheta)=c I+c \frac{\iota}{2}(\vartheta-I)
$$

From (2), (3), and (12b) the respective inventory supply functions must satisfy:

\footnotetext{
${ }^{9}$ One implication of this assumption is that the aggregate cost of holding a stock of given size falls as the stock is subdivided into more holdings, each of smaller size.

${ }^{10}$ The charge per unit is equal to the facility's average cost of storage.

${ }^{11}$ Since intermediate values between 0 and 1 can be interpreted as partial pooling, we will permit $\iota$ to be any number in the closed interval $[0,1]$.
} 


$$
\begin{aligned}
& I^{a}\left(P_{1}\right)=\frac{E\left[\tilde{P}_{2} \mid P_{1}\right]-P_{1}}{c}-\frac{\vartheta^{a}}{2}, \\
& I^{b}\left(w_{1}, \theta\right)=\frac{E\left[\tilde{P}_{2} \mid w_{1}, \theta\right]-P_{1}}{c}-\frac{\imath \vartheta^{b}}{2},
\end{aligned}
$$

where $\vartheta^{x}$ represents total inventories less the amount held by one firm of type $x$.

The expectation of future price held by informed investors can be computed from (7) after first inverting the demand function in (11):

$$
E\left[P_{2} \mid w_{1}, \theta\right]=E\left[h\left(\vartheta-k-w_{2}\right) \mid w_{1}, \theta\right]=h(Q-2 k)-P_{1}-y_{2},
$$

where $y_{2}=h\left(w_{1}+E\left[w_{2} \mid \theta\right]\right)$. The leading terms on the right-hand side of (14) are directly observable by uninformed traders. But, to read the price expectations of informed investors, uninformed traders also need to know the quantity $y_{2}$, which represents the informed investors' view of the sum of demand shocks. To see whether $P_{1}$ actually reveals that additional information, combine (6) and (8) using the demand and inventory functions given by (11) and (13), to obtain:

$$
k+\frac{1}{h} P_{1}+\frac{m}{c}\left(E\left[\tilde{P}_{2} \mid P_{1}\right]-P_{1}\right)+\frac{\iota(1-m-n)}{2} \vartheta-Q=-w_{1}-\frac{n}{c}\left(E\left[\tilde{P}_{2} \mid w_{1}, \theta\right]-P_{1}\right),
$$

which, after substituting for $\vartheta$ and using (14) to evaluate $E\left[P_{2} \mid w_{1}, \theta\right]$, is equivalent to: ${ }^{12}$

$$
P_{1}\left(\frac{(1-\phi)}{h}-\frac{(2 n+m)}{c}\right)+\frac{m}{c} E\left[\tilde{P}_{2} \mid P_{1}\right]+Q\left(\frac{n h-c(1-\phi)}{c}\right)-k\left(\frac{2 n h-c(1-\phi)}{c}\right)=y_{1},
$$

where:

$$
y_{1}=\left(\frac{n h-c(1-\phi)}{c}\right) w_{1}+\frac{n h}{c} E\left[w_{2} \mid \theta\right]
$$

and $\phi=\frac{\iota(1-m-n)}{2}$.

${ }^{12} \vartheta$ is the sum of (13a) and (13b): $\vartheta=\frac{1}{c\left(1-\frac{(1-m-n)}{2}\right)}\left\{m \times E\left[\left(\tilde{P}_{2} \mid P_{1}\right)-P_{1}\right]+n \times E\left[\left(\tilde{P}_{2} \mid w_{1}, \theta\right)-P_{1}\right]\right\}$ 
The left-hand side of (16) depends only on known parameters and $P_{1}$. Thus, $P_{1}$ reveals to uninformed traders the quantity $y_{1}$, which is the wrong linear combination of demand shocks; so $y_{1}$ deviates systematically from the desired quantity, $y_{2}$. The spot price therefore sends a garbled signal to uninformed traders, who cannot, without additional information, read very precisely the expectations of informed traders.

Before examining factors that determine the degree of garbling, it is worth noting that, if uninformed traders are able to observe both $P_{1}$ and $w_{1}$ (the first-period demand shock) they are much better informed because the value of $E\left[w_{2} \mid \theta\right]$, and therefore $y_{2}$, can then be inferred from (16). Only in that event will the private information of informed traders be fully revealed. Although we have assumed that uninformed traders are not able to observe $w_{1}$ directly, there are two ways in which they might acquire such information indirectly. First, if the total volume of inventories is announced (say by an omniscient government agency), then any firm that observes $P_{1}$ can use the inventory data to infer $w_{1}$ from (6) and (11). Alternatively, any firm that happens to be aware of the industry-wide inventory cost function and that also knows that its own storage is billed at the average cost of service could infer total inventory (and hence $w_{1}$ ) by simply inverting the cost function. This highlights the pivotal role that information regarding physical stocks and inventory costs plays in leveraging the information revealed by the spot price. Either type of information (i.e., physical stocks or inventory costs) may be sufficient to produce a fully revealing equilibrium. ${ }^{13}$

In practice, neither of these paths toward a fully revealing equilibrium may be easy to achieve. Although government agencies do announce estimated inventory levels for many commodities, these estimates are based on incomplete surveys, published after significant lags,

\footnotetext{
${ }^{13}$ One may be tempted to assume that any traders who can observe inventory numbers would simply join the ranks of the informed traders, leaving those without that information among the uninformed. There is a subtle but important difference, however, between becoming informed via public inventory pronouncements versus basic research into the shocks that affect the system. Indeed, the former extinguishes the latter, since knowledge of inventories produces a fully revealing equilibrium in which there is no private return to basic research.
} 
and are typically subject to revision. ${ }^{14}$ The other possibility, that uninformed traders manage to accurately read industry aggregates from their individual storage costs, also seems doubtfuland becomes impossible if inventories are kept separate and not pooled (our special case of $\iota=0)$. Where circumstances do permit either of these possibilities, then the spot market equilibrium we model would indeed be fully revealing, and thereby eliminate the incentive to gather private information as well as the incentive to engage in speculative trading in the futures market. For the balance of this paper, and because we believe that the alternative hypothesis holds greater interest, we maintain the assumption that uninformed traders do not have accurate inventory data, and therefore are not able to precisely read the expectations of informed traders.

Despite the garbling that occurs under this scenario, some information is nevertheless revealed. By inspection of (17), it is apparent that $y_{1}$ converges to $y_{2}$ as $\frac{n h}{c}$ grows large relative to $\frac{1+m+n}{2}$. This suggests that the magnitude of the average difference in beliefs may depend systematically on these underlying factors (i.e., inventory costs, the elasticity of demand, and the relative number of informed investors who participate in the market)—a possibility that we examine in more detail below.

Even where garbling occurs, the equilibrium difference in beliefs is on average zero because positive and negative differences cancel out. ${ }^{15}$ In either case, the discrepancy puts uninformed traders at a disadvantage, with effects that do not cancel out. Therefore, rather than using $E\left[\Delta\left(w_{1}, \theta\right)\right]$ to measure the average difference in beliefs, it is better to focus on the mean

\footnotetext{
${ }^{14}$ The U.S. Energy Information Administration, for example, releases crude oil and refined product inventory data (for the US only) with weekly, monthly, and yearly lags, with improved accuracy at the longer lags. Although revisions to the weekly stock data are typically small (1-2 percent), much larger revisions occasionally occur for particular products (e.g., 9 percent on average for stocks of ultra-low sulfur distillate in 2006 and 18 percent on average for stocks of reformulated motor gasoline in 2007 (the latest two years for which EIA has prepared summary reports of such revisions). However, revisions to the reported weekly change in petroleum stocks are drastically higher, averaging 52 percent in 2006 and 80 percent in 2007. See Heppner and Breslin (2009) for more detail. Baumeister and Kilian (2011) show that revisions to the EIA data constitute "news" and are not themselves forecastable.

${ }^{15}$ Information available to uninformed bidders is not biased, because $E\left[w_{2}\right]=E\left[E\left[w_{2} \mid \theta\right]\right]$.
} 
squared error, which accumulates the absolute difference between informed and uninformed traders:

$$
D I F F=E\left[\Delta\left(w_{1}, \theta\right)\right]^{2}=\operatorname{var}\left(y_{2} \mid y_{1}\right)=\sigma_{y_{2}}^{2}\left(1-r_{y_{2} y_{1}}^{2}\right)
$$

where:

$$
\sigma_{y_{2}}^{2} \stackrel{\text { def }}{=} \operatorname{var}\left(y_{2}\right) \quad \text { and } \quad r_{y_{1} y_{2}} \stackrel{\text { def }}{=} \frac{\operatorname{cov}\left(y_{1} y_{2}\right)}{\sqrt{\operatorname{var}\left(y_{1}\right)} \sqrt{\operatorname{var}\left(y_{2}\right)}}
$$

The second equality in (18) is based on Grossman's (1977) proof; the third equality is simply a change of notation to highlight the importance of the correlation between $y_{1}$ and $y_{2} .{ }^{16}$ For convenience, we will refer to the two parts of DIFF as the "range of variation" $\left(\sigma_{y_{2}}^{2}\right)$ and "degree of garbling" $\left(1-r_{y_{1} y_{2}}^{2}\right)$.

The average difference in beliefs can be evaluated using (18) and the expressions given previously for $y_{1}$ and $y_{2}$, which imply the following:

$$
\begin{aligned}
& \operatorname{var}\left(y_{2}\right)=h^{2}\left(\operatorname{var}\left(\widetilde{w}_{1}\right)+\operatorname{var}\left(E\left[\widetilde{w}_{2} \mid \theta\right]\right)\right)=h^{2} \sigma^{2}\left(1+\rho^{2}\right) \\
& \operatorname{var}\left(y_{1}\right)=\left(\frac{n h}{c}-(1-\phi)\right)^{2} \operatorname{var}\left(\widetilde{w}_{1}\right)+\left(\frac{n h}{c}\right)^{2} \operatorname{var}\left(E\left[\widetilde{w}_{2} \mid \theta\right]\right)=\sigma^{2}\left[\left(\frac{n h}{c}\right)^{2}\left(1+\rho^{2}\right)-\frac{2 n h(1-\phi)}{c}+(1-\phi)^{2}\right] \\
& \operatorname{cov}\left(y_{1} y_{2}\right)=\sigma^{2}\left[\frac{n h^{2}}{c}\left(1+\rho^{2}\right)-h(1-\phi)\right] \geq 0
\end{aligned}
$$

where we have used the independence of $w_{1}$ and $w_{2}$, and where the symbol $\rho$ denotes the simple correlation coefficient between $\theta$ and $w_{2}$-which measures the quality of information available to informed investors. The fact that the demand curve is downward sloping $(h<0)$ implies that the covariance must be nonnegative. After substituting these terms in (18), DIFF takes the form:

$$
D I F F=h^{2} \sigma^{2}\left(1+\rho^{2}\right)\left\{1-\frac{\left[n h^{2}(1+\rho)^{2}-(1-\phi) c h\right]^{2}}{\left[n^{2} h^{2}\left(1+\rho^{2}\right)-2 \operatorname{cnh}(1-\phi)+c^{2}(1-\phi)^{2}\right]\left[h^{2}\left(1+\rho^{2}\right)\right]}\right\} .
$$

\footnotetext{
${ }^{16}$ Grossman's original proof is not dependent on the number of traders, as shown in our appendix.
} 
After some manipulation this expression reduces to:

$$
D I F F=\frac{\sigma^{2} c^{2} h^{2}(1-\phi)^{2}(R-1)}{n^{2} h^{2} R-2 c n h(1-\phi)+c^{2}(1-\phi)^{2}}
$$

where $R=1+\rho^{2}$.

\section{The Quality of Information Revealed by Spot Prices}

In this section we explore the quality of information that is revealed to uninformed traders in the spot market, as measured by DIFF, the average difference in beliefs. At one extreme, DIFF $=0$ if all information is revealed, an outcome that occurs only if $r_{y_{1} y_{2}}^{2}=1$ (cf. (18)). At the other extreme $\left(r_{y_{1} y_{2}}^{2}=0\right)$ no information is revealed and the maximal value of DIFF $=h^{2} \sigma^{2}(1+$ $\left.\rho^{2}\right)$, which approaches infinity as the volatility of price fluctuations $(h \sigma)$ grows.

For any given commodity, the size of the actual difference in beliefs will fall somewhere between these extremes, depending on several fundamental characteristics of the commodity in question, including inventory cost $(c)$, elasticity of demand $(h)$, volatility of demand shocks $(\sigma)$, and the quality of information available to informed investors $(\rho)$. In addition, the numbers of firms $(m, n)$ play a direct role. For present purposes, we shall assume that the numbers of firms are determined exogenously, like the other structural parameters. Later, we will relax this assumption and permit the number of informed and uninformed investors to be determined endogenously, which has additional implications for the average difference in beliefs and how it might vary across commodities.

Volatility of Demand:

Using (23), we evaluate and sign the partial derivatives of DIFF with respect to each factor. We begin with the volatility of demand shocks $\left(\sigma^{2}\right)$, which has by far the simplest impact because it affects only the range of variation. Indeed, DIFF is simply proportional to $\sigma^{2}$ (cf. (23)), and we find:

$$
\frac{\partial D I F F}{\partial \sigma^{2}}=h^{2}(1+\rho)^{2}\left(1-r_{y_{1} y_{2}}^{2}\right) \geq 0
$$


which shows that the average difference in beliefs varies directly with the volatility of demand, and more specifically that, for any given degree of garbling $\left(1-r_{y_{1} y_{2}}^{2}>0\right)$, the resulting difference in beliefs is magnified by inelastic demand (large $|h|)$ and the accuracy of the informed investors' forecasting model $(\rho)$.

$\underline{\text { Inventory Cost: }}$

We turn next to the cost of carrying the commodity in inventory $(c)$, which is also fairly simple because by inspection of (23) it affects DIFF only through the degree of garbling, not the range of variation. As shown in the appendix, higher inventory cost increases the degree of garbling, which implies:

$$
\frac{\partial D I F F}{\partial c}>0
$$

It also follows immediately from (23) that the average difference in beliefs vanishes as inventory cost goes to zero:

$$
D I F F_{c=0}=0 .
$$

Higher inventory costs thus increase the average difference in beliefs by increasing the degree of garbling. Holding all else equal, we may therefore expect larger differences in beliefs to persist in markets for commodities that are more expensive to store (like electricity, natural gas, and feeder cattle) and during periods when storage capacity is in short supply.

The effect of fluctuations in convenience yield is also determined by (25). As mentioned previously, $c$ represents the cost of holding the commodity net of convenience yield. Therefore, any increase in convenience yield, with all else equal, will cause $c$ to fall, which in turn decreases the equilibrium difference in beliefs.

\section{Forecast Accuracy:}

The accuracy of informed investors' prediction of the future demand shock is given by $\rho$, which measures the correlation between $\theta$ and $w_{2}$. The first component of DIFF (range of 
variation) is, by inspection of (23), clearly increasing in $\rho$. The second component of DIFF (degree of garbling) is also increasing in $\rho$ (proof in appendix). Together, these results imply:

$$
\frac{\partial D I F F}{\partial \rho}>0
$$

Thus, the more accurate is the informed forecast, the greater on average will be the difference in beliefs between informed and uninformed traders-holding all other factors constant. Elasticity of Demand:

Variations in the slope of the demand curve $(h)$ exert countervailing forces on the two components of DIFF. The range of variation is increasing in $h$-just as it was increasing in the accuracy of the demand forecast $(\rho)$, but the degree of garbling decreases in $h$, unlike the influence of $\rho .{ }^{17}$ As shown in the appendix, the second force dominates and the overall effect is unambiguous:

$$
\frac{\partial D I F F}{\partial h}<0
$$

It is useful to restate this result in terms of the elasticity of demand. At any given price level, demand becomes more elastic as $h$ increases (toward zero). Therefore (28) implies that the average difference in beliefs, holding all else equal, should be highest for commodities with the least elastic demand.

Numbers of Traders:

Like inventory costs, the numbers of traders $(m, n)$ affect DIFF only through the second component (garbling). As shown in the appendix, any increase in the number of informed traders reduces the degree of garbling, whereas any increase in the number of uninformed traders increases the degree of garbling. Therefore, we have:

$$
\frac{\partial D I F F}{\partial m} \geq 0 \quad \text { (with strict equality if and only if } \iota=0 \text { ) }
$$

\footnotetext{
${ }^{17}$ This difference is due to the fact that any change in $h$ impacts the expected level of demand in both periods, whereas the accuracy of the demand forecast only pertains to demand in the second period.
} 


$$
\frac{\partial D I F F}{\partial n}<0
$$

Based on (29) and (30), we would expect a larger average difference in beliefs to persist in commodity markets in which relatively few informed traders participate. But, we are also able to show (see appendix) that, if the numbers of informed and uninformed firms increase in fixed proportion, the equilibrium difference in beliefs will fall:

$$
\frac{\partial D I F F}{\partial(m+n) \mid m / n=\text { constant }}<0 \text {. }
$$

Thus, a greater number of traders will increase the degree of revelation even if the average trader is no better informed.

The impact of each factor on the equilibrium difference in beliefs is illustrated in Figure 2 (next page), which describes the comparative static properties for a benchmark case in which parameter values are set as follows: $c=1 ; \sigma^{2}=2 ; \rho=0.89 ; h=-2 ; m=n=5 ;$ and $\iota=1$. The impact of each factor, varied independently, is monotonic and can be seen to cause the difference in beliefs to increase by a factor of 3 (or more) over the range of variation shown in Figure 2. 


\section{Figure 2: Comparative Static Impacts on Equilibrium Difference in Beliefs}
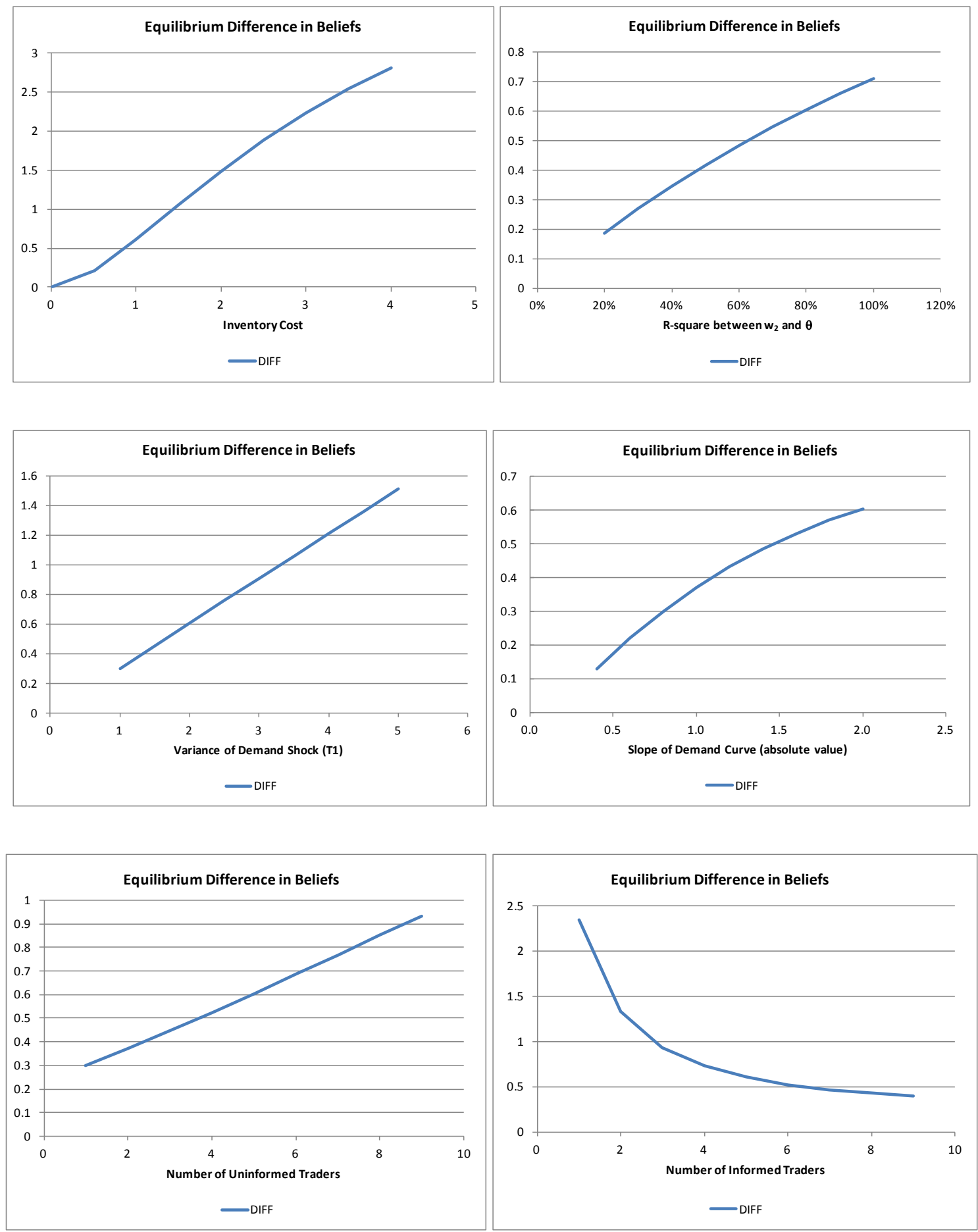
Figure 2 (continued)

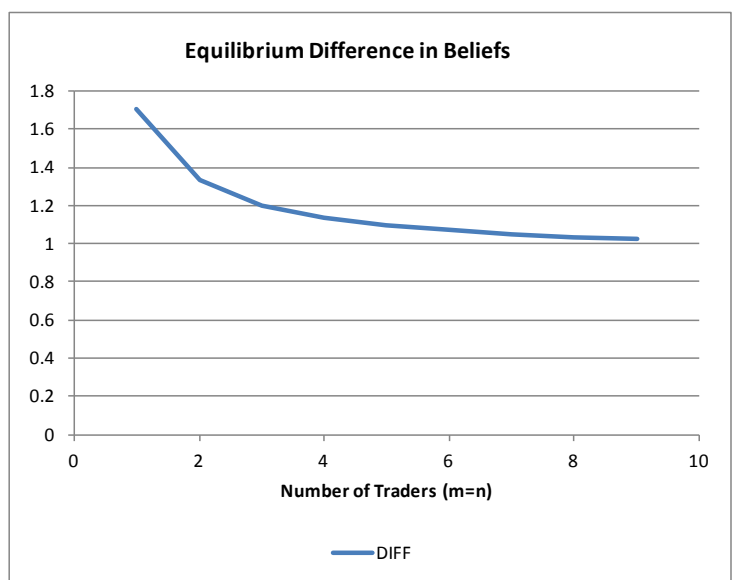

\section{The Impact of Passive Investors}

In this section we add a new investor category_passive investors in the physical commodity - to the analysis and examine their impact on the revelation of information and the magnitude of equilibrium differences in beliefs. We assume the passive investors seek to diversify their broader portfolio of assets (e.g., equities, fixed-income, real estate, etc.) by purchasing a given quantity of the commodity in question during the first period, to be sold in the second period. ${ }^{18}$ Since their investment decision is taken independently of $P_{1}$ and their expectations regarding $P_{2}$, passive investors do not engage in speculation. A real world analogue to our passive investor would be commodity index funds that invest in physically backed ETFs, and the like 19

To be specific, we assume passive investors purchase a quantity $\tilde{q}$, of the commodity in the first period, where $\tilde{q} \sim N\left(\mu_{q}, \sigma_{q}\right)$. For convenience, we will also assume that this quantity is independent of $w_{1}$ and $w_{2}$. Informed investors can observe the value, $q$, that passive investors

\footnotetext{
${ }^{18}$ Assuming that index investors purchase a fixed nominal value of the commodity gives similar results.

${ }^{19}$ Our characterization of index investors is admittedly a generalization, but one that is consistent with many previous studies of index funds. As reported by Irwin and Sanders (2011), Barclay Capital's 2010 survey of commodity index investors found $52 \%$ to be investing for diversification or hedging motives, versus $31 \%$ who were seeking "absolute returns."
} 
select from this distribution, but uninformed investors are aware only that the value is drawn independently from the given distribution.

As before, we wish to see the degree to which $P_{1}$ reveals the informed investors' price expectations. Since none of the steps leading to (14) are affected by the presence of passive investors, the informed investors' expectation is still given by:

$$
E\left[P_{2} \mid w_{1}, \theta\right]=E\left[h\left(\vartheta-k-w_{2}\right) \mid w_{1}, \theta\right]=h(Q-2 k)-P_{1}-y_{2}
$$

where $y_{2}=h\left(w_{1}+E\left[w_{2} \mid \theta\right]\right)$. The leading terms on the right-hand side of (32) are directly observable by uninformed traders. But, to read the price expectations of informed investors, uninformed traders still need to know the quantity $y_{2}$, which represents the informed investors' view of the sum of demand shocks. To see what $P_{1}$ actually reveals to uninformed investors, we first adjust (8) to account for the portion of inventory held by passive investors, after which (15) takes the slightly modified form:

$$
k+\frac{1}{h} P_{1}+\frac{m}{c}\left(E\left[\tilde{P}_{2} \mid P_{1}\right]-P_{1}\right)+\frac{\iota(1-m-n)}{2} \vartheta-Q=-\left(w_{1}+q\right)-\frac{n}{c}\left(E\left[\tilde{P}_{2} \mid w_{1}, \theta\right]-P_{1}\right) .
$$

And (16) then becomes:

$$
P_{1}\left(\frac{(1-\phi)}{h}-\frac{(2 n+m)}{c}\right)+\frac{m}{c} E\left[\tilde{P}_{2} \mid P_{1}\right]+Q\left(\frac{n h-c(1-\phi)}{c}\right)-k\left(\frac{2 n h-c(1-\phi)}{c}\right)=y_{1}^{\prime},
$$

where $y_{1}^{\prime}=y_{1}-q$.

The left-hand side of (34) depends only on known parameters and $P_{1}$. Thus, $P_{1}$ reveals to uninformed traders the quantity $y_{1}-q$, which is again the wrong linear combination of the demand shocks.

In fact, the situation is worse than before because passive inventory $(q)$ is now compounded with $y_{1}$, and therefore further obscures the pertinent information regarding demand shocks. One way to see this is to realize that now, even if uninformed investors were assumed to know the total volume of inventories, which reveals $w_{1}$ via (6) and (11), they would 
not be able to infer the value of $E\left[w_{2} \mid \theta\right]$ from (34). Only if they also knew the portion of total inventories held by passive investors would the expectations of informed investors be fully revealed. This is in direct contrast to our previous result.

It is important to realize that it is the volatility of passive inventories, not their size, that impedes the revelation of information. ${ }^{20}$ This can be confirmed by again evaluating the equilibrium difference in beliefs and observing the comparative statics. By the same argument stated previously, we now have:

$$
D I F F=\operatorname{var}\left(y_{2} \mid y_{1}^{\prime}\right)=\sigma_{y_{2}}^{2}\left(1-r_{y_{2}}^{2} y_{1}^{\prime}\right)
$$

Because $y_{2}$ has not changed, $\sigma_{y_{2}}^{2}$ is still given by (20). Moreover, because the added element of $y_{1}^{\prime}$ (i.e. $q$ ) is independent of both components of $y_{2}$ (i.e., $w_{1}$ and $w_{2}$ ), the covariance also has not changed and is still given by (22). However, the variance of $y_{1}^{\prime}$ is inflated due to the effect of the passive inventory:

$\operatorname{var}\left(y_{1}^{\prime}\right)=\sigma^{2}\left[\delta+\left(\frac{n h}{c}\right)^{2}\left(1+\rho^{2}\right)-\frac{2 n h(1-\phi)}{c}+(1-\phi)^{2}\right]$

where $\delta=\sigma_{q}^{2} / \sigma^{2}$ measures the variance of passive inventories relative to the variance of consumer demand. Since $\operatorname{var}\left(y_{1}^{\prime}\right)$ is increasing in $\delta$, whereas $\operatorname{var}\left(y_{2}\right)$ and $\operatorname{cov}\left(y_{1}^{\prime} y_{2}\right)$ are independent of $\delta$, it follows immediately from (35) that DIFF must also be increasing in the volatility of passive inventories:

$$
\frac{\partial D I F F}{\partial \delta}>0
$$

Even though they are not speculating themselves, passive investors increase the scope for speculative futures trading because their unpredictable behavior impairs the revelation of information, which in turn increases the magnitude of equilibrium differences in rational investors' beliefs.

\footnotetext{
${ }^{20}$ Compare to DeLong, et. al. (1990), where it is also the unpredictability of noise traders' positions that permits prices to diverge significantly from fundamental values, despite the presence of rational arbitrageurs.
} 
The impact of the volatility of passive investor positions on the equilibrium difference in beliefs is illustrated in Figure 3 (using the same benchmark parameter values as Figure 2). As the relative volatility of passive holdings $(\delta)$ increases from 0 to 3 , the equilibrium difference in beliefs widens by roughly $60 \%$.

Figure 3: Impact of Passive Investors on Equilibrium Difference in Beliefs

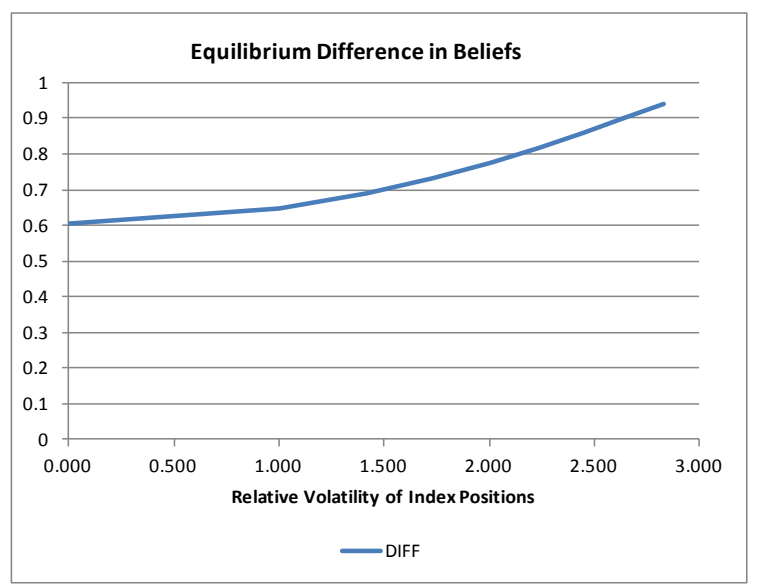

For any given value of $\delta$, information revelation responds to exogenous variations in the other structural parameters almost exactly as before. This is confirmed by re-evaluating the comparative statics. After substituting (36) into (35) and simplifying, we obtain:

$$
D I F F=\sigma^{2}\left[\frac{c^{2} h^{2}\left[(1-\phi)^{2}(R-1)+\delta R\right]}{c^{2} \delta+n^{2} h^{2} R-2 c n h(1-\phi)+c^{2}(1-\phi)^{2}}\right]
$$

where $R=\left(1+\rho^{2}\right)$. By differentiating (38) with $\delta>0$ we are, as before, able to show (see appendix):

$$
\begin{aligned}
& \frac{\partial D I F F}{\partial \sigma^{2}} \geq 0 \\
& \frac{\partial D I F F}{\partial c}>0 \\
& \frac{\partial D I F F}{\partial \rho}>0 .
\end{aligned}
$$




$$
\begin{aligned}
& \frac{\partial D I F F}{\partial h}<0 . \\
& \frac{\partial D I F F}{\partial n}<0 \\
& \frac{\partial D I F F}{\partial(m+n) \mid m / n=\text { constant }}<0 .
\end{aligned}
$$

The only deviation from prior results is the following:

$$
\frac{\partial D I F F}{\partial m}<=>0
$$

which for $\delta=0$ was shown to be non-negative. ${ }^{21}$ Thus, the presence of passive investors introduces the possibility that the equilibrium difference in beliefs actually shrinks as the number of uninformed investors grows. (Numerical calculations show, however, that this is an unlikely outcome that arises only in extreme cases).

All results reported so far assume that the numbers of traders $(m, n)$ are determined exogenously. In the next section we address the incentive for traders to enter this market, the incentive for them to become informed, and the impact of these endogenous decisions on the equilibrium difference in beliefs.

\section{The Return to Private Information and Entry of Informed Traders}

To the extent that revelation of private information is incomplete, informed traders enjoy an advantage relative to uninformed traders and earn higher expected profits:

$$
E\left[\pi^{b}\left(\widetilde{w}_{1}, \tilde{\theta}, \tilde{q}\right)\right] \geq E\left[\pi^{a}\left(\widetilde{P}_{1}=P_{1}^{e}\left(\widetilde{w}_{1}, \tilde{\theta}, \tilde{q}\right)\right)\right]
$$

\footnotetext{
${ }^{21}$ As before, $\frac{\partial D I F F}{\partial m}=0$ whenever $\iota=0$. The number of uninformed traders does not matter if inventories are held separately, even in the presence of passive index investors.
} 
where the expectation is taken over the joint distribution of $w_{1}, \theta$, and $q .{ }^{22}$ As long as this difference exceeds the cost of becoming informed, there is an incentive for uninformed firms to become informed (or for additional informed firms to enter the market). In either case, as we have already shown, the effect is to reduce the difference in beliefs. Thus, if the profit differential varies directly with the difference in beliefs, and if firms are rational, the entry of informed firms will continue until the difference in expected profits is eventually reduced to the cost of becoming informed.

We characterize here the long-run equilibrium of this process for the special case where $\iota=0$ (separate inventories) and $\delta=0$ (no unpredictable passive inventories), but there is nothing particularly unique about this case except the simplicity of the derivation. ${ }^{23}$ Given $\iota=0$, the expected difference in profits between informed and uninformed traders is given by: ${ }^{24}$

$$
D I F F \pi=E\left[\pi^{b}-\pi^{a}\right]=\frac{1}{2 c} D I F F,
$$

where DIFF represents the average difference in beliefs, as defined above.

We assume that entry (or exit) of informed traders occurs until the incremental profit accruing to private information falls (rises) to equal the cost of becoming informed, denoted $z$. Recalling the determinants of $D I F F$ discussed above, this allows us to close the model and determine the equilibrium number of informed traders $\left(n^{e}\right)$ via the zero profit condition:

$$
\frac{1}{2 c} \operatorname{DIFF}\left(c, \sigma^{2}, \rho, h, m, n^{e}\right) \equiv z
$$

Taking the total differential of (41) yields:

$$
\frac{\partial \frac{1}{2 c} D I F F}{\partial c} d c+\frac{1}{2 c}\left(\frac{\partial D I F F}{\partial \sigma^{2}} d \sigma^{2}+\frac{\partial D I F F}{\partial h} d h+\frac{\partial D I F F}{\partial \rho} d \rho+\frac{\partial D I F F}{\partial m} d m+\frac{\partial D I F F}{\partial n^{e}} d n^{e}\right)=d z
$$

\footnotetext{
${ }^{22}$ The strict equality applies only if either the distribution of $w_{1}$ is degenerate or the signal carries no information ( $\theta$ uncorrelated with $w_{1}$ ). The proof is straightforward and follows the same argument used by Grossman (1977).

${ }^{23}$ Recall that all comparative static properties of the model hold for all values $\iota \epsilon[0,1]$.

${ }^{24}$ Grossman derived this expression assuming $m=n=1$, but his derivation does not depend in any way on the number of firms.
} 
which permits determination of the separate effect of each structural parameter on the equilibrium number of informed traders:

$$
\begin{aligned}
& \frac{d n^{e}}{d \sigma^{2}}=-\frac{\partial D I F F / \partial \sigma^{2}}{\partial D I F F / \partial n^{e}}>0 \quad \text { (i.e. larger shocks } \rightarrow \text { more informed traders) } \\
& \frac{d n^{e}}{d h}=-\frac{\partial D I F F / \partial h}{\partial D I F F / \partial n^{e}}<0 \quad \text { (i.e. more elastic demand } \rightarrow \text { fewer informed traders) } \\
& \frac{d n^{e}}{d \rho}=-\frac{\partial D I F F / \partial \rho}{\partial D I F F / \partial n^{e}}>0 \quad \text { (i.e. better forecasts } \rightarrow \text { more informed traders) } \\
& \frac{d n^{e}}{d m}=-\frac{\partial D I F F / \partial m}{\partial D I F F / \partial n^{e}}=0 \quad \text { (i.e. more uninformed traders } \rightarrow \text { no impact) } \\
& \frac{d n^{e}}{d z}=\frac{1}{\partial D I F F / \partial n^{e}}<0 \quad \text { (i.e. costlier forecasts } \rightarrow \text { fewer informed traders) } \\
& \frac{d n^{e}}{d c}=-\frac{(\partial D I F F / \partial c-D I F F / c)}{\partial D I F F / \partial n^{e}}=\frac{(1-\varepsilon)(D I F F / c)}{\partial D I F F / \partial n^{e}} \gtrless 0 \text { as } \varepsilon \gtrless 1,
\end{aligned}
$$

where $\varepsilon$ is the elasticity of the difference in beliefs with respect to inventory cost. Thus, if the difference of opinion is inelastic with respect to inventory cost, costlier inventories mean fewer informed traders.

Because the difference in beliefs provides the incentive for speculative futures trading, the size of that incentive is determined in equilibrium by (33), which can be written as:

$$
D I F F=2 c z .
$$

Equilibrium in the spot market, after allowing for the entry of informed investors, therefore implies that the incentive for speculative futures trading is dependent on just two factors-the cost of inventories net of convenience yield and the cost of information-and must be increasing in each. The net cost of holding inventories may depend both on the physical properties of the commodity in question as well as factors that contribute to a convenience yield. The cost of information is determined by the stability of factors that influence demand and supply as well as the transparency of the industry. Both factors may be expected to vary across 
time as well as across commodities, which provides the means for an empirical test of the theory. It remains for future research to test the hypothesis that resulting variations in beliefs between informed and uninformed traders cause systematic variations in the extent of speculative trading in futures contracts, and to examine the related hypothesis that, due to the entry of informed traders, variations in the other factors (elasticity and volatility of demand, and the quality of information) that would influence the difference in beliefs holding numbers of traders constant, actually play no role in determining the extent of speculative trading.

\section{Conclusion}

Much attention has focused recently on the degree of financial speculation in various commodity futures markets. In our view, the existence and scope of that activity may be due as much to characteristics of the underlying commodities as to characteristics of the traders involved. Commodity characteristics that impede the revelation of information via spot trading, like high inventory costs or opaque public data sources, sustain differences in beliefs that give rise to speculative trading in the futures market. To the extent that speculative futures trading is perceived to be excessive, the cure for the problem (or at least its cause) may be sought in the underlying spot market.

Many concrete initiatives to enhance the information available to support trading in spot markets can be cited in this regard, especially within the realm of energy markets. Recent efforts by the Joint Organizations Data Initiative (JODI) to produce a transparent and open access global database on monthly crude oil and refined product stocks and flows is one example ${ }^{25}$, although China is a notable holdout that has not yet elected to release its own inventory data. The International Organization of Securities Commissions' (2012) ongoing consultative report on the functioning and oversight of oil price reporting agencies, prepared in response to the G20 Leaders' Cannes Summit Final Declaration, is yet another example. And

\footnotetext{
${ }^{25}$ Available online at http://www.jodidata.org/.
} 
the U.N. Statistical Commission's (2011) recently released report, "International Recommendations for Energy Statistics," represents an even broader effort to systematically increase the scope, quality, and transparency of data regarding the supply and use of energy. Similar initiatives apply to many non-energy markets, such as the G20's new reporting program (Agricultural Market Information System) to enhance food market transparency, ${ }^{26}$ and the imminent opening in China of a public spot-market trading platform for the rare-earth metals, a market that up to now has remained largely opaque because rare earths have not been traded in public markets. ${ }^{27}$

If governments desire to decrease the amount of speculative trading in futures markets (and it appears that they do), progress reached through initiatives that shine a brighter light on fundamentals of the underlying spot markets may be an effective complement, and perhaps substitute, for placing broader restrictions (e.g., reduced position limits, higher margin requirements, and outright prohibitions) on futures trading itself. The former approach works by reducing the demand for speculation, whereas the latter can only hope to suppress it.

\footnotetext{
${ }^{26}$ Available online at the AMIS website: $\mathrm{http}: / /$ www.amis-outlook.org/home/en/.

${ }^{27}$ As reported by Yap (2012).
} 


\section{List of References}

Alquist, Ron and Lutz Kilian. 2010. "What do We Learn from the Price of Crude Oil Futures." Journal of Applied Econometrics 25:539-573.

Baumeister, Christiane and Lutz Kilian. 2011. "Real-time Forecasts of the Real Price of Oil." Working paper, July 8.

De Long, J. Bradford, Andrei Shleifer, Lawrence Summers, and Robert Waldmann. 1990. "Noise Trader Risk in Financial Markets." Journal of Political Economy 98:4, 703-738.

Feldstein, Martin. 2008. "We Can Lower Oil Prices Now." The Wall Street Journal, July 1.

Grossman, Sanford. 1977. "On the Existence of Futures Markets, Noisy Rational Expectations, and Informational Externalities." Review of Economic Studies 64, 431-449.

Grossman, Sanford and Joseph E. Stiglitz. 1980. "On the Impossibility of Informationally Efficient Markets." American Economic Review 70:3, 393-408.

Heppner, Tammy G. and Matthew M. Breslin. 2009. "Accuracy of Petroleum Supply Data." Petroleum Supply Monthly, (U.S. Energy Information Administration) February: vii-xxvii.

Hong, Harrison and Jeremy C. Stein. 2007. "Disagreement and the Stock Market." Journal of Economic Perspectives 21:2, 109-128.

Hotelling, Harold. 1931. "The Economics of Exhaustible Resources." Journal of Political Economy 39:2, 137-175.

International Organization of Securities Commissions. 2012. Functioning and Oversight of Oil Price Reporting Agencies: Consultation Report. CR04/12. Madrid, Spain: International Organization of Securities Commissions. http://www.iosco.org/library/pubdocs/pdf/IOSCOPD375.pdf (accessed September 6, 2012).

Irwin, Scott H. and Dwight R. Sanders. 2011. "Index Funds, Financialization, and Commodity Futures Markets." Applied Economic Perspectives and Policy 33:1, 1-31.

Kilian, Lutz and Daniel P. Murphy. 2012. "The Role of Inventories and Speculative Trading in the Global Market for Crude Oil." Working paper, July 26.

Milgrom, Paul and Nancy Stokey. 1982. "Information, Trade and Common Knowledge." Journal of Economic Theory 26, 17-27.

Pleven, Liam and Matt Moffett. 2012. "Rain Falls on Corn's Parade." The Wall Street Journal, January 13.

Stein, Jeremy C. 1987. "Informational Externalities and Welfare-reducing Speculation." Journal of Political Economy 95:6, 1123-1145.

Tirole, Jean. 1982. "On the Possibility of Speculation under Rational Expectations." Econometrica 50:5, 1163-1181. 
U.N. Statistical Commission. 2011. International Recommendations for Energy Statistics (IRES). Draft version. New York, NY: U.N. Statistics Division. http://unstats.un.org/unsd/statcom/doc11/BG-IRES.pdf (accessed September 6, 2012).

Working, Holbrook. 1942. "Quotations on Commodity Futures as Price Forecasts." Econometrica 10:1, 39-52.

Yap, Chuin-Wei. 2012. "China Plans Rare-Earth Trading Platform." The Wall Street Journal, July 12 . 


\section{Appendix}

A. Proof that $D I F F=\sigma_{y_{2}}^{2}\left(1-r_{y_{1} y_{2}}^{2}\right)$.

Combining equilibrium conditions (6) and (7) with the linear demand forms in (11), we have: $I=k+h^{-1} P_{2}+w_{2}=Q-\left(k+h^{-1} P_{1}+w_{1}\right)$, which can be solved for: $P_{2}=h\left(Q-2 k-w_{1}-w_{2}\right)-P_{1}$. Taking the conditional expectation gives: $E\left[\tilde{P}_{2} \mid w_{1}, \theta\right]=$ $h\left[Q-2 k-E\left(P_{1} \mid w_{1}, \theta\right)\right]-\tilde{y}_{2}$, where $\tilde{y}_{2}$ is given by (14). That describes one side of the "beliefs" that enter into DIFF. To get the other side, we note the relationship:

$E\left[\tilde{P}_{2} \mid P_{1}\right]=E\left\{E\left[\tilde{P}_{2} \mid w_{1}, \theta\right] \mid P_{1}\right\}=E\left(\left\{h\left[Q-2 k-E\left(P_{1} \mid w_{1}, \theta\right)\right]-\tilde{y}_{2}\right\} \mid P_{1}\right)$, where we have substituted for $E\left[\tilde{P}_{2} \mid w_{1}, \theta\right]$ from the previous step. After taking the expectation in the last expression, we have: $E\left[\tilde{P}_{2} \mid P_{1}\right]=h\left[Q-2 k-E\left(P_{1} \mid w_{1}, \theta\right)\right]-E\left(\tilde{y}_{2} \mid P_{1}\right)$. By definition, the difference in beliefs is computed as the difference between the two: $\Delta\left(w_{1}, \theta\right)=$ $E\left[\tilde{P}_{2} \mid w_{1}, \theta\right]-E\left[\tilde{P}_{2} \mid P_{1}\right]=E\left(\tilde{y}_{2} \mid P_{1}\right)-\tilde{y}_{2}=E\left(\tilde{y}_{2} \mid y_{1}\right)-\tilde{y}_{2}$, where the last step is based on the fact that $P_{1}$ and $y_{1}$ are one-to-one (which can be inferred from (16)).

Recall the definition, $D I F F=E\left[\Delta\left(w_{1}, \theta\right)\right]^{2}$. By a well-known property of the variance of a random variable, we may write: $E\left\{\left[\Delta\left(w_{1}, \theta\right)\right]^{2} \mid y_{1}\right\}=\operatorname{Var}\left[\Delta\left(w_{1}, \theta\right) \mid y_{1}\right]+$ $\left\{E\left[\Delta\left(w_{1}, \theta\right) \mid y_{1}\right]\right\}^{2}$. But, because $E\left[\Delta\left(w_{1}, \theta\right) \mid y_{1}\right]=0$, this implies $E\left\{\left[\Delta\left(w_{1}, \theta\right)\right]^{2} \mid y_{1}\right\}=$ $\operatorname{Var}\left[\Delta\left(w_{1}, \theta\right) \mid y_{1}\right]=\operatorname{Var}\left[E\left\{\left(\tilde{y}_{2} \mid y_{1}\right)-\tilde{y}_{2}\right\} \mid y_{1}\right]=\operatorname{Var}\left(\tilde{y}_{2} \mid y_{1}\right)=\sigma_{y_{2}}^{2}\left(1-r_{y_{1} y_{2}}^{2}\right)$, where the next to last step is due to the fact that $E\left[\left(\tilde{y}_{2} \mid y_{1}\right) \mid y_{1}\right]$ is non-stochastic. Since $\tilde{y}_{2}$ and $\tilde{y}_{1}$ are jointly normally distributed, the last expression does not depend on $y_{1}$, and we can write: $\operatorname{Var}\left[\Delta\left(w_{1}, \theta\right)\right]=\sigma_{y_{2}}^{2}\left(1-r_{y_{1} y_{2}}^{2}\right)$. QED.

B. Proofs of (39a)-(39g).

Here we present proofs for the general case, $\delta \geq 0$, which includes the potential impact of volatile commodity index fund inventories. Proofs for the special case without index funds can be obtained by setting $\delta=0$. 


\section{$\underline{\partial D I F F / \partial c>0}$.}

Taking the derivative of (38) with respect to c gives:

$$
\begin{aligned}
& \frac{\partial D I F F}{\partial c} \propto {\left[2 \sigma^{2} c h^{2}(1-\phi)^{2}(R-1)+\delta R\right]\left[c^{2} \delta+n^{2} h^{2} R-2 c n h(1-\phi)+c^{2}(1-\phi)^{2}\right] } \\
&-2\left[c \delta+c(1-\phi)^{2}-n h(1-\phi)\right] \sigma^{2} c^{2} h^{2}\left[(1-\phi)^{2}(R-1)+\delta R\right]
\end{aligned}
$$

After dividing by $\sigma^{2} c h^{2}(1-\phi)^{2}(R-1)+\delta R$, which is positive, this implies:

$$
\begin{aligned}
\frac{\partial D I F F}{\partial c} & \propto 2\left[c^{2} \delta+n^{2} h^{2} R-2 c n h(1-\phi)+c^{2}(1-\phi)^{2}\right]-2 c\left[c \delta+c(1-\phi)^{2}-n h(1-\phi)\right] \\
& =2 n^{2} h^{2} R-2 c n h(1-\phi)>0
\end{aligned}
$$

where the inequality is due to $n \geq 1, c>0, R \geq 1, \phi<0$, and $h<0$. QED.

\section{$\underline{\partial D I F F / \partial n<0}$.}

Recall that $(1-\phi)$ is a function of $n$, with $\frac{\partial(1-\phi)}{\partial n}=\frac{\iota}{2}$. Differentiating (38) with respect to $n$ therefore yields:

$$
\begin{aligned}
\frac{\partial D I F F}{\partial n} \propto \iota(1-\phi) & \sigma^{2} c^{2} h^{2}(R-1)\left[c^{2} \delta+n^{2} h^{2} R-2 c n h(1-\phi)+c^{2}(1-\phi)^{2}\right] \\
& -2\left[n h^{2} R-c h\left(\frac{\iota}{2} n+(1-\phi)\right)+\frac{\iota}{2} c^{2}(1-\phi)\right]\left[\sigma^{2} c^{2} h^{2}(1-\phi)^{2}(R-1)+\delta R\right] .
\end{aligned}
$$

After dividing by $\sigma^{2} c^{2} h^{2}(1-\phi)(R-1)$, which is positive, and simplifying, this implies:

$$
\begin{aligned}
& \frac{\partial D I F F}{\partial n} \propto \iota\left[c^{2} \delta+n^{2} h^{2} R-2 c n h(1-\phi)+c^{2}(1-\phi)^{2}\right] \\
& -\left[(1-\phi)+\frac{\delta R}{c^{2} h^{2}(1-\phi)(R-1)}\right]\left[2 n h^{2} R-2 c h(1-\phi)-\iota c n h+\iota c^{2}(1-\phi)\right] \\
& \quad=-\left(n h^{2} R-\operatorname{ch}(1-\phi)\right)(1+m+n-\imath n)-\frac{2 \delta n R^{2}}{c^{2}(1-\phi)(R-1)}+\frac{2 \delta R}{c h(R-1)}+\frac{\iota \delta n R}{c h(1-\phi)(R-1)}-\frac{\iota \delta R}{h^{2}(R-1)}<0,
\end{aligned}
$$

where leading product is negative and each of the last four terms is negative because $h<0$. QED. 


\section{$\underline{\partial D I F F / \partial m<>0}$.}

Recall that $(1-\phi)$ is a function of $m$, with $\frac{\partial(1-\phi)}{\partial m}=\frac{\iota}{2}$. Differentiating (38) with respect to $m$ therefore yields:

$$
\begin{array}{r}
\frac{\partial D I F F}{\partial m} \propto \iota(1-\phi) \sigma^{2} c^{2} h^{2}(R-1)\left[c^{2} \delta+n^{2} h^{2} R-2 c n h(1-\phi)+c^{2}(1-\phi)^{2}\right] \\
-2\left[\frac{\iota}{2} c^{2}(1-\phi)-\frac{\iota}{2} c n h\right] \sigma^{2} c^{2} h^{2}\left[(1-\phi)^{2}(R-1)+\delta R\right] .
\end{array}
$$

After dividing by $\sigma^{2} c^{2} h^{2}(1-\phi)(R-1)$, which is positive, this implies:

$$
\begin{aligned}
\frac{\partial D I F F}{\partial m} \propto \iota\left[c^{2} \delta+\right. & \left.n^{2} h^{2} R-2 c n h(1-\phi)+c^{2}(1-\phi)^{2}\right]-\left[\iota c^{2}(1-\phi)^{2}-\iota c n h(1-\phi)\right] \\
& +\frac{\iota c n h \delta R}{(1-\phi)(R-1)}-\frac{\iota c^{2} \delta R}{R-1} \\
= & \iota n^{2} h^{2} R-\iota c n h(1-\phi)-\frac{\iota c \delta}{R-1}\left(c-\frac{n h R}{(1-\phi)}\right)<=>0 .
\end{aligned}
$$

The sign of $\frac{\partial D I F F}{\partial m}$ depends on the value of $\delta$. The two leading terms in the derivative are both positive, but the last term is negative and varies directly with $\delta$. Thus, when the volatility of passive index investment becomes large enough, the equilibrium difference in beliefs will vary inversely with the number of uninformed traders. Note: if $\delta=0$ (i.e., no unpredictable index fund investment), then $\frac{\partial D I F F}{\partial m} \geq 0$. And, if $\iota=0$ (i.e., separate inventories), then $\frac{\partial D I F F}{\partial m}=0$. QED.

$\underline{\partial D I F F / \partial \rho>0}$.

We demonstrate that $\partial D I F F / \partial R>0$ and use the fact that $|\rho|$ is one-to-one with $R=$ $\left(1+\rho^{2}\right)$. First, we differentiate (38) with respect to $R$ :

$$
\begin{aligned}
\frac{\partial D I F F}{\partial R} \propto \sigma^{2}\left[c^{2} h^{2}(1-\phi)^{2}+\delta\right]\left[c^{2} \delta+n^{2} h^{2} R\right. & \left.-2 c n h(1-\phi)+c^{2}(1-\phi)^{2}\right] \\
& -\sigma^{2} n^{2} h^{2}\left\{c^{2} h^{2}\left[(1-\phi)^{2}(R-1)+\delta R\right]\right\} .
\end{aligned}
$$

After dividing by $\sigma^{2} c^{2} h^{2}(1-\phi)^{2}$, which is positive, this implies: 


$$
\begin{aligned}
\frac{\partial D I F F}{\partial R} \propto c^{2} \delta+n^{2} h^{2} R-2 c n h(1-\phi)+c^{2}(1-\phi)^{2} & \\
& +\frac{\delta^{2} c^{2}+\delta n^{2} h^{2} R-2 \delta c n h(1-\phi)+\delta c^{2}(1-\phi)^{2}}{c^{2} h^{2}(1-\phi)^{2}}-n^{2} h^{2}(R-1)-\frac{n^{2} h^{2} \delta R}{c^{2} h^{2}(1-\phi)^{2}} \\
= & n^{2} h^{2}-2 \operatorname{cnh}(1-\phi)+c^{2}(1-\phi)^{2}+c^{2} \delta+\frac{\delta^{2}}{h^{2}(1-\phi)^{2}}-\frac{2 \delta n}{c h(1-\phi)}+\frac{\delta}{c h^{2}}>0,
\end{aligned}
$$

where the inequality follows because each component is positive due to $h<0$. QED.

\section{$\underline{\partial D I F F / \partial h<0 .}$.}

Differentiating (38) with respect to $h$ yields:

$$
\begin{aligned}
\frac{\partial D I F F}{\partial h} \propto 2 \sigma^{2} c^{2} h\left[(1-\phi)^{2}(R-1)\right. & +\delta R]\left[c^{2} \delta+n^{2} h^{2} R-2 c n h(1-\phi)+c^{2}(1-\phi)^{2}\right] \\
& -2\left[n^{2} h R-c n(1-\phi)\right]\left[\sigma^{2} c^{2} h^{2}\left[(1-\phi)^{2}(R-1)+\delta R\right]\right] .
\end{aligned}
$$

After dividing by $-\sigma^{2} c^{2} h\left[(1-\phi)^{2}(R-1)+\delta R\right]$, which is positive, this implies:

$\frac{\partial D I F F}{\partial h} \propto 2 c n h(1-\phi)-2 c^{2}\left[(1-\phi)^{2}+\delta\right]<0$. QED.

$\underline{\partial D I F F / \partial(m+n)<0}$ (assuming $m / n$ constant).

Define $\lambda=\frac{m}{n}$. It follows that $(1-\phi)=1-\frac{\iota}{2}+\frac{\iota}{2} n(1+\lambda)$, and $\frac{\partial(1-\phi)}{\partial n}=\frac{\iota}{2}(1+\lambda)$, holding $\lambda$ constant. Differentiation of (38) with respect to $n$, but treating $\lambda$ as constant, then yields:

$$
\begin{aligned}
& \frac{\partial D I F F}{\partial m+n\left(\frac{m}{n} \text { constant }\right)} \propto \iota(1+\lambda) \sigma^{2} c^{2} h^{2}(1-\phi)(R-1)\left[c^{2} \delta+n^{2} h^{2} R-2 c n h(1-\phi)+c^{2}(1-\phi)^{2}\right] \\
& -2\left[n h^{2} R-\operatorname{ch}(1-\phi)-\frac{\iota}{2} \operatorname{chn}(1+\lambda)+\frac{\iota}{2}(1+\lambda) c^{2}(1-\phi)\right]\left[\sigma^{2} c^{2} h^{2}\left[(1-\phi)^{2}(R-1)+\delta R\right]\right] .
\end{aligned}
$$

After dividing by $\sigma^{2} c^{2} h^{2}(1-\phi)(R-1)$, which is positive, and collecting terms, we have:

$$
\frac{\partial D I F F}{\partial m+n \mid m / n \text { constant }} \propto\left[n h^{2} R-\operatorname{ch}(1-\phi)\right](\iota-2)-\frac{\iota(1+\lambda) c^{2} \delta}{(R-1)}-\frac{2 \delta n h^{2} R^{2}}{(1-\phi)(R-1)}+\frac{2 \delta \operatorname{ch}(1-\phi)}{(1-\phi)(R-1)}+\frac{\iota \delta R \operatorname{cnh}(1+\lambda)}{(1-\phi)(R-1)}<0
$$


where we have used: $\iota n(1+\lambda)=\iota-2 \phi$. The inequality follows from the fact that $0 \leq \iota \leq 1, \phi<0, h<0$, and $R>1$. QED. 